\title{
Beyond billiard balls: Transnational flows, cultural diversity and digital games
}

\author{
Aphra Kerr
}

\section{Introduction}

Current mass media policy and regulation in Western Europe is primarily state-based and increasingly based on the presumption that a competitive market will maximise individual choice and diversity. Policy interventions are primarily justified in terms of specific market failures including concentration of producers in the marketplace, the need to financially reward content developers financially for their work and issues related to distribution bottlenecks. ${ }^{1}$ Nevertheless, it is clear that at the national and European levels, public interest and cultural arguments also inform policy development and regulation. New media, including online and offline digital games, represent a new area for policy makers at the national and international levels. This chapter aims to contribute to our understanding of how digital games operate as markets and as social and cultural activities in order to inform discussions about the need for policy interventions.

Two significant challenges face us as we attempt to assess the usefulness and applicability of a "cultural diversity" discourse in the contemporary media context. Firstly globalisation, with its associated flows of people, goods, services, technology and ideas, has challenged how academics and regulators think about culture and the media, and has shifted attention away from the national to the transnational, the translocal and the regional. ${ }^{2}$ Thinking about culture and cultural diversity has had to shift from the national frame to a range of registers above and below the national. Theorisations about the impact of globalisation on cultures have recognised that while in some contexts there may be cultural homogenisation, there may also be cultural heterogeneity or indeed new hybrid forms of culture may be formed. ${ }^{3}$ Scholars have recognised that there are multiple centres of global

${ }^{1}$ Nicholas Garnham, Emancipation, the Media and Modernity: Arguments about the Media and Social Theory, Oxford: Oxford University Press, 2000, at p. 59.

${ }^{2}$ Arjun Appadurai, "Disjuncture and Difference in the Global Cultural Economy" in Mike Featherstone (ed.), Global Culture: Nationalism, Globalisation and Modernity, London: Sage, 1990, pp. 295-310; Myria Georgiou, "Diasporic Media Across Europe: Multicultural Societies and the Universalism-Particularism Continuum" (2005) Journal of Ethnic and Migration Studies 31:3, pp. 481-498.

${ }^{3}$ Terhi Rantanen, The Media and Globalisation, London: Sage, 2005; Aphra Kerr, "Transnational flows: media use by Poles in Ireland" in John Horgan, Barbara O'Connor and Helena Sheehan, Mapping Irish Media: 
cultural production and emerging geo-linguistic and geo-cultural markets in different regions of the world. Further, the protection and promotion of homogenous "national" cultures has been recognised as a historically contingent, and perhaps Western, construct. Thus cultural diversity is less about protecting national cultures and more about promoting a diversity of opinions, languages, ethnicities and races. It is less about the West versus the rest in terms of trade flows and more about recognising the complexities of global production in late capitalism and the dominance of new centres of production.

Secondly, the emergence of new technologies of distribution, from the Internet and wireless to satellite and cable, have called into question the role, efficacy and scope of media regulation, particularly at a national level. In Western Europe the last twenty years has seen the introduction of competition in broadcasting and telecommunications and increasing numbers of private producers, new channels and content. As content production and distribution becomes digital it has become more difficult to regulate their flows. This is particularly the case when it comes to content like online games, internet websites and satellite television. As a result, regulators have introduced co-regulation and self-regulation in collaboration with industry and shifted the burden of responsibility for content suitability and access to both gatekeepers and the individual consumer. This approach is based on the presumption that the key actors involved will act in the interests of the public, that codes of conduct are enforced and that users have the critical literacy skills to make decisions about content.

As a relatively new sub-sector of the cultural industries (dating from the 1970s in terms of being a professional industry) digital games have to date largely escaped state regulation and where regulation has existed it has related to the, in some cases voluntary, submission of games for classification and labelling of content. Some countries have stricter classification systems and some are based in law, as in Germany and in the UK. To a large degree, however, the digital games industry is self-regulated by professional bodies which are dominated by publishers. As third-generation video consoles (e.g. PS3, Xbox 360 and Wii) move to develop more online services, and content becomes available as a download service rather than solely on $\mathrm{CD}$ or cartridge, regulators are becoming increasingly aware and concerned about the types of services and content being provided and the adequacy and efficacy of measures in place to protect minors and vulnerable users.

In this chapter, I adopt a qualitative approach to exploring cultural diversity and digital games. I explore contexts of cultural diversity using a range of secondary sources, from academia and the wider public domain, and based on this analysis I attempt to identify gaps which academics and regulators might wish to explore further in relation to the necessity or not to introduce interventions to encourage cultural diversity in digital game environments.

\section{What do we mean by cultural diversity in relation to the media?}

Denis McQuail notes that "[d]iversity is neutral as to content. It is a valuation of variety". He goes on to note that discussions on diversity in the media usually explore diversity of provision, diversity of content/representation and diversity of

Critical Explorations, Dublin: University College Dublin Press, 2007, pp. 173-188; Kevin Robins, The Challenge of Transcultural Diversities, Strasbourg: Council of Europe Publishing, 2006. 
audiences. ${ }^{4}$ The relationship between these categories is problematic. Studies using quantitative methods for measuring diversity have found the relationship between ownership and content in particular to be far from straightforward. ${ }^{5}$ Feintuck notes that "there may possibly be strong contingent relationships between diversity of ownership and diversity of output, or between monopoly of ownership and homogeneity of product in terms of political perspective or lack of diversity in programme range, but such relationships remain contingent rather than necessary". 6 Similarly Hesmondhalgh notes that diversity of provision and ownership is not necessarily related to diversity of content and to date scholars have failed to convincingly demonstrate, beyond specific examples, the linkages between these types of diversity. ${ }^{7}$

As Mosco notes, multiplicity of channels and output is not the same thing as diversity of opinion. ${ }^{8}$ For many academics diversity is far from neutral as regards content. Much writing on diversity and the media from a sociology perspective is concerned with ways to understand and evaluate the quality of media content and identify who gets represented in the media, by whom and to what ends. Both academic writing and policy on diversity in general, and cultural diversity in particular, argue that it is desirable "that the media system overall should exhibit a range of output that reflects the diversity of the society, especially in the key dimensions of region, politics, religion, ethnicity, culture and so on. Media channels should be open to new movements and ideas and give reasonable access to small minorities". 9 Thus cultural diversity is seen as a normative ideal for many and linked for some to a properly functioning public sphere and democracy.

European media regulators have a long history of applying "cultural diversity" as a value and goal of media policy. From the establishment of Channel 4 in the UK to cater to minority interests, the establishment of S4C in Wales and TG4 in Ireland to cater to minority language interests, and the establishment of public service funds to support minority interest media production it is clear that cultural diversity has been an important goal in relation to public service broadcasting and programming development in some European countries since the 1970s. At a European level, the report of UNESCO's MacBride Commission in the 1970s on a New World Information and Communication Order (NWICO) demonstrates that pan-national interest in cultural issues and the media is not new or uncontested internationally. ${ }^{10}$ More recently, the European Commission's "Television without Frontiers" Directive, the MEDIA programme and at the international level, the UNESCO Convention on the Protection and Promotion of the Diversity of Cultural Expressions ${ }^{11}$ signal attempts to treat trade in audiovisual services and the media in cultural as well as economic terms, despite the obvious tensions this raises. The broadcasting industry is also active in

${ }^{4}$ Denis McQuail, McQuail's Mass Communication Theory, 5th edn, London: Sage, 2005, at p. 197.

${ }^{5}$ Daniel G. McDonald and John Dimmick, "The Conceptualisation and Measurement of Diversity" (2003) Communication Research 30:1, pp. 60-79.

${ }^{6}$ Mike Feintuck, Media Regulation, Public Interest and the Law, Edinburgh: Edinburgh University Press, 1999 , at p. 44.

${ }^{7}$ David Hesmondhalgh, The Cultural Industries, London: Sage, 2002, at p. 75.

${ }^{8}$ Vincent Mosco, The Political Economy of Communication, London: Sage, 1996, at p. 258.

${ }^{9}$ Ibid. at p. 166.

${ }^{10}$ Ted Madger, "International agreements and the regulation of world communication" in James Curran and David Morley (eds.), Media and Cultural Theory, London: Routledge, 2006, pp. 164-176.

11 UNESCO Convention on the Protection and Promotion of the Diversity of Cultural Expressions, as adopted 20 October 2005, and entered into force 8 March 2007. 
this area. The European Broadcasting Union has introduced a diversity toolkit for factual programmes in public service broadcasting and has established a Eurovision Intercultural and Diversity Group involving those responsible for the diversity policies of a number of European broadcasters. ${ }^{12}$ It is interesting that for the most part these policies focus on mass media and indigenous national cultures.

We need to explore closely what academics and policy makers mean when they deploy the concept of "cultural diversity" in policy documents and discourse, and try to think through how it might be deployed in the context of new media and virtual environments. Three issues in particular are important to consider. The first is that the concept of cultural diversity should not be framed to promote diversity among nations and "national cultures" at the expense of cultures within nations or minority interests. Indeed since most policies related to media and culture are developed at a national level in Europe, one needs to attend to "what cultures" and "whose cultures" are being promoted by such policies. Secondly, as Raj Isar cautions, "everywhere understandings of cultural diversity as a strategic notion tend to favour 'billiard ball' representations of cultures as neatly bounded wholes whose contents are given and static - hence mainly to be 'protected' and 'preserved'." 13 While there certainly are aspects of cultures that may need protection and preservation we should be careful when framing discussions and policies to promote cultural diversity that we take into account that cultures are far from stable and thrive on interaction. Finally, cultural diversity policies related to the media and creative expressions in contemporary societies need to take into account more than the production of content. Policies which support national production by companies, must also attend to international distribution issues and power in that industry or may fail ultimately to address the unevenness of cultural flows and access.

In the 1970s and 1980s it was thought that cultural diversity could be simply quantified and that more was better, in terms of diversity of the workforce, programmes and characters in programmes. This led to many surveys and much form filling, but when policy and practice were compared many became disenchanted with this approach. Simply hiring more women or people from minority groups did little to address imbalances in power or programming policy in organisations. The academic conceptualisation of cultural diversity has since moved towards a more fluid concept and academic work has adopted a qualitative approach to examining practice rather than policy in organisations. ${ }^{14}$ This is not to say that surveys and data are unimportant, but rather that we need to go beyond numbers of companies and measures of diversity to critically explore what is being produced in particular contexts, by whom and who is getting to access it.

\section{What do we know about cultural diversity and digital games?}

Discussions about diversity and digital games have to date mainly focused on gender diversity. ${ }^{15}$ This agenda has been driven by academics keen to critique the "militarised masculinity" often paraded by the games industry at industry

${ }^{12}$ See http://www.ebu.ch/en/union/under_banners/CulturalDiversity_2008.php.

13 Yudhishthir Raj Isar, "Cultural Diversity" (2006) Theory, Culture and Society 23:2-3, pp. 372-375.

14 Ben O'Loughlin, “The Operationalization of the Concept 'Cultural Diversity' in British Television Policy and Governance”, CRESC Working Paper Series, Working Paper No 27, November 2006.

${ }^{15}$ Justine Cassell and Henry Jenkins (eds.), From Barbie to Mortal Kombat: Gender and Computer Games, Cambridge, MA: MIT Press, 1998. 
events and in high profile games. ${ }^{16}$ Sociologists meanwhile have published ethnographic research about the gendered nature of the games industry and games culture. ${ }^{17}$ Individual designers have published books encouraging more diversity in games design. ${ }^{18}$ The issue has received some attention from the industry and attempts have been made to develop more "pink games" for girls and some female-only game development companies have been set up. The International Game Development Association website has a diversity section but the focus is on diversity of the workforce. They have established a "Women in Games special interest group" and have conducted surveys which have identified very low levels of diversity in the workplace in US companies in particular..$^{19}$ In the UK and the US, these surveys indicate that over three-quarters of the workforce are male, young and white..$^{20}$ None of these initiatives have to date resulted in any radical policies or widespread change in the gender profile of the development industry.

Research on digital games and cultural diversity, or other forms of diversity, is relatively rare. There have been some attempts to explore the factors influencing the development of specific national game development industries ${ }^{21}$ and, more recently, some work on the hybridity of video games in terms of their ability to mix aspects of different cultures. Mia Consalvo notes that the games produced by the Japanese firm Square Enix, specifically the Final Fantasy series, are exemplars of careful processes of localisation or "glocalisation", a mixing of the global and the local. She argues that the industry "is a hybrid" of Japanese and American culture while also acknowledging that the main corporations have established "technoregions" with their own barriers to access and to flow.22 A search of the main game journals and conference proceedings yielded few papers on the topic and those that have been published, tend to focus on the use of Modding and Web 2.0 tools to aid diversity of content. ${ }^{23}$ Similarly a search of the industry website Gamasutra yielded little apart from commentary on French tax

${ }^{16}$ Gillian Skirrow, Hellivision: An Analysis of Video Games. High Theory, Low Culture: Analysing Popular Television and Film, Manchester: Manchester University Press, 1986; Stephen Kline, Nick Dyer-Witheford and Greig de Peuter, Digital Play: The Interaction of Technology, Culture, and Marketing, Montreal: McGill-Queen's University Press, 2003.

17 Jo Bryce and Jason Rutter, Killing like a Girl: Gendered Gaming and Girl Gamers' Visibility. Tampere: Tampere University Press, 2002; Jo Bryce and Jason Rutter, "Gender Dynamics and the Social and Spatial Organisation of Computer Gaming" (2003) Leisure Studies 22:1, pp. 1-15; Aphra Kerr, "(Girls) Women Just Want to Have Fun: A Study of Adult Female Gamers" in Marinka Copier and Joost Raessens (eds.), Level Up: Digital Games Research Conference, Utrecht: University of Utrecht Press, 2003, pp. 270-287.

18 Sheri Graner Ray, Gender Inclusive Design: Expanding the Market, Hingham, MA: Charles River Media, 2004.

${ }^{19}$ See http://www.igda.org/diversity/.

${ }^{20}$ See http://www.igda.org/diversity/report.php.

21 Yuko Aoyama and Hiro Izushi, "Hardware Gimmick or Cultural Innovation? Technological, Cultural and Social Foundations of the Japanese Video Game Industry" (2003) Research Policy 32:3, pp. 423-444; Nick Dyer-Witheford and Zena Sharman, "The Political Economy of Canada's Video and Computer Game Industry" (2005) Canadian Journal of Communication 30:2, pp. 187-210; Mutlu Binark and Günseli Bayraktutan-Sütcü, "The Political and Cultural Economy of the Turkish Digital Game Development: What Turkish Game Developers Really Need?", Paper presented at the 7th Association for Cultural Studies, International Crossroads in Cultural Studies Conference, 3-7 July 2008, University of West Indies, Kingston, Jamaica; Dal Yong Jin and Florence Chee, “Age of New Media Empires: A Critical Interpretation of the Korean Online Game Industry" (2008) Games and Culture 3:1, pp. 38-58.

${ }_{22}$ Mia Consalvo, “Console Video Games and Global Corporations: Creating a Hybrid Culture" (2006) New Media and Society 8:1, pp. 117-137.

${ }^{23}$ See the contribution of Mira Burri-Nenova to this volume. 
breaks and the MEDIA programme funding for the development of games which focus on "cultural diversity and heritage of Europe". ${ }^{24}$

Given the lack of existing work on cultural diversity in games, this chapter has a modest aim. It suggests that if we are to contribute to an understanding of cultural diversity and games, or indeed cultural diversity and virtual worlds, we might use McQuail's three categories ${ }^{25}$ including diversity of provision, diversity of content/representation and diversity of audiences as a starting point, while trying to go beyond mere quantitative approaches to these three categories. However, these categories need to be extended to consider diversity within the workforce, flows of content between regions, the development of user generated content and, finally, national and regional laws.

Combining these issues, we have the following categories:

1. Diversity of production (to include concentration/market share and ownership of companies, geographical spread of main companies, diversity of workforce, flows between regions, national or regional supports for production);

2. Diversity of content and representation (genres, user generated content);

3. Diversity of game players (by region, gender, age, ethnicity, race, and nationality).

In what follows I will attempt to draw together some of the available data to sketch, at least in part, some of the issues emerging in the field of digital games.

\section{The cultural diversity of digital games production}

In this chapter, digital games refer to digitally produced and distributed games played on video consoles, personal computers (PCs) and mobile handsets. Currently most digital games offer some degree of online capability. The trend across all these platforms is to add either wired or wireless multiplayer features and to facilitate anything from small groups to thousands of people playing simultaneously. Another trend is towards the development of multiple business models including retail, try before you buy, downloads, subscription services and pay per play. Massively multiplayer online games (MMOG), for example, require full time community support services, extensive server facilities and regular updates to their players engaged and paying monthly subscriptions. Indeed, there is a continuum of online games available; from games played exclusively offline with minimal web-supported community services, such as a website offering top score charts and forums, to games played exclusively online with extensive community support services, such as MMOGs.

There is extensive evidence to suggest that digital games can be situated within the broader category of the cultural industries. ${ }^{26}$ This category includes those institutions involved in the industrial production of cultural artefacts and symbolic goods and includes television, radio, the cinema, newspapers, magazine and book publishing, the music recording and publishing industry, advertising and the performing arts. The category does not include the "software industry" and certain

\footnotetext{
${ }^{24}$ See http://www.gamasutra.com/. For more on the French initiatives, see the contribution of Christoph Beat Graber to this volume.

${ }^{25}$ McQuail, supra note 4, at p. 197.

${ }^{26}$ Hesmondhalgh, supra note 7; Kline et al., supra note 16; Aphra Kerr, The Business and Culture of Digital Games, London: Sage, 2006; David Hesmondhalgh, "Cultural and Creative Industries" in Tony Bennett and John Frow (eds.), The SAGE Handbook of Cultural Analysis, London: Sage, 2007, pp. 552-569. See also the contribution of Christoph Beat Graber to this volume.
} 
arts and crafts which are included in some policy definitions of the "creative industries". ${ }^{27}$ While digital games are a "form of software" and rely on interaction, the type of content they produce, the production process and the role of digital games as a recreational and leisure activity in society places them much closer to existing audiovisual and cultural industries. Further, when one examines the changes taking place within the traditional cultural industries as they move online and move from analogue to digital production as well as distribution, we can see certain sub-categories of media and software converging rather than diverging.

Kerr sought to divide the digital games industry into four separate segments: the console, the standard PC, the MMOG and the casual/mini. ${ }^{28}$ This conceptualisation still largely makes sense from a political economic perspective, even with the development of online distribution and the multiplication of revenue models in the last five years. This approach notes that if we look at the structure and ownership of companies in the digital games industry, the use of technology, and the production cycle, we can see that there are four distinct approaches or paths that companies take to bring a game to market. If a developer targets the console segment then one must deal with the hardware manufacturers, pay them a licence fee to access their proprietary technology and all content must go through their quality approval process. Games produced for this market are relatively costly and go through a complex selection process to get into the production pipeline. These hardware manufacturers are American and Japanese companies and the technology is largely closed and proprietary.

In the PC segment, there are fewer barriers to entry but the standard PC market is as a result very competitive. Further, while this segment is significant in value terms in Europe and some Asian countries, the PC market is less important in the largest markets, the US and Japan. The third segment is the MMOG market, which requires significant upfront investment and continuous support to customers. Currently the market is dominated by a small number of games and producers, some of whom are active in other segments, like Sony and Blizzard Entertainment, who develop and support World of Warcraft. Finally, we have the casual games market, which has much lower barriers to market, is technologically open and highly competitive. Costs and margins are low, production cycles short and the battle for attention is crucial. One might expect that in the PC, MMOG and casual markets there would be much greater diversity of production than in the console market given their different market structures.

A report on global trade flows by UNESCO in 2005 found that in terms of goods trade in video games the annual growth rate grew rapidly between 1994 and 2002 and that exports from countries in transition and from East Asia accounted for significant growth in exports. This signals the increasing importance of distributed production in the industry more generally, and the rise of South Korea and China as centres of production more specifically. ${ }^{29}$ China, Germany, Hungary, Japan and Mexico were the top five global exporters of video games and the manufacture of games hardware in China, Hungary and Mexico contributed significantly here. And where are these goods being exported to? The report clearly

\footnotetext{
${ }_{27}$ Garnham, supra note 1; Hesmondhalgh, supra note 7; Aphra Kerr, "From Boston to Berlin: Creativity and Digital Media Industries in the Celtic Tiger" in Geert Lovink and Ned Rossiter (eds.), My Creativity Reader: A Critique of Creative Industries, Amsterdam: Institute of Network Cultures, 2007, pp. 111-124.

${ }^{28}$ Kerr, supra note 26.

${ }^{29}$ UNESCO, International Flows of Selected Cultural Goods and Services, 1994-2003: Defining and Capturing the Flows of Global Cultural Trade, Paris: UNESCO, 2005, at p. 42.
} 
signals that a limited number of high-income countries are the major importers dominated by the USA and followed by France, Germany, Hong Kong, China and the United Kingdom. The report found that data on the trade of audiovisual services was difficult to collate due to a lack of specificity. What data exists would suggest that the US dominates followed by the UK.

In order to investigate the cultural diversity of digital games production one needs to attempt to differentiate between where the production is geographically located and where the ownership or control of production and publishing is located. One needs also to separate hardware and software. Increasingly, as in the film business, the production of digital games hardware and disks occurs in offshore low-cost locations like China, Taiwan, and Hungary while software production is in part moving to Eastern Europe, China and Canada. However, the ownership of these offshore companies is still in the hands of a relatively small number of companies. Castronova notes that "[o]utside of the United States and Asia, the synthetic world market is largely one of demand rather than supply" ${ }^{30}$ Previous work by this author examining the digital games industry found that from the late 1990s and throughout this decade, the industry has become increasingly concentrated, with a smaller number of companies controlling the development of hardware and software in the console part of the industry in particular. Given that this is the largest part of the industry in value terms, particularly in the US market, this concentration of power and wealth in a small number of American and Japanese companies is significant. ${ }^{31}$ One consequence of such concentration is the creation of barriers to entry preventing or making it very difficult for many first-time independent developers to reach the market. ${ }^{32}$

A detailed empirical study of digital game production networks by Jennifer Johns indicates that the concentration of power and value in the industry is continuing. She found that "while hardware production is conducted at the global scale, software production tends to operate within three supra-regional contexts." 33 These regions are demarcated by technological, economic, social and cultural barriers. The regions for game production are the US, Europe and Japan and the top fourteen publishers of console software originate from the US, France and Japan. Thus even as the industry has moved towards a distributed production model including off-shoring and outsourcing, key publishing, management, marketing and distribution services are located and controlled by a small number of privately owned multinational companies.

If one was to examine the top publishers by earnings, the top three in 2004 (Electronic Arts, Sony and Nintendo) had significantly more earnings than the rest and they are dominated by American and Japanese companies. ${ }^{34}$ The top three publishers in the console segment of course also control the hardware platforms, pace of change and quality of all content which gets published on their systems.

\footnotetext{
${ }^{30}$ Edward Castronova, Synthetic Worlds: The Business and Culture of Online Games, Chicago: University of Chicago Press, 2005, at p. 127.

31 Aphra Kerr and Roddy Flynn, "Revisiting Globalisation through the Movie and Digital Games Industries" (2003) Convergence: The Journal of Research into New Media Technologies 9:2, pp. 91-113. See also Kerr, supra note 26 .

32 Aphra Kerr, "Loading... Please Wait. Ireland and the Global Games Industry" (2002) STeM Working Paper No 1.

33 Jennifer Johns, "Video Games Production Networks: Value Capture, Power Relations and Embeddedness" (2006) Journal of Economic Geography 6:2, pp. 151-180, at p. 153.

34 Cristina Teipen, "Work and Employment in Creative Industries: The Video Games Industry in Germany, Sweden and Poland" (2008) Economic and Industrial Democracy 29:3, pp. 309-335.
} 
Independent publishers must deal with these hardware manufacturers if they are to get their content onto these systems. More recent data on earnings and profitability would signal that the dominance in software publishing of a small number of publishers registered in the US and Japan is continuing. ${ }^{35}$ Only Ubisoft and Atari/InfoGrames (both French) are challenging the dominance of American and Japanese companies in the top ten software publishers in digital games. At the same time, some academic scholars have found that despite the falling numbers of companies, competition between the big three companies, particularly in the console segment is strong, and there are disincentives to cooperating. ${ }^{36} \mathrm{~A}$ historical review of lifecycles in the console segment shows that while there have been three to five competing systems in each cycle from 1976 to today, the companies involved have changed. Companies that have gained a dominant position in a particular life cycle tend to abuse their position and neglect content quality issues allowing new entrants to enter in the next life cycle. ${ }^{37}$ Thus while a small number of companies from a small number of companies dominate this segment, competition between them appears to be strong.

Why focus on the publishers? Publishers play a crucial role in the games development production chain through financing both in-house and third-party game developments. Developers usually fund their productions using advance finance from publishers and thus what gets published and distributed on the three main console platforms is decided by a small number of individuals in a small number of firms. In 2002, a UK report noted that publishers were consolidating, and while US and French publishers were able to obtain investment in their local markets, British publishers found sourcing finance more difficult and therefore lacked scale compared to international competitors. ${ }^{38}$ Comparative research on French and British publishing industries also argued that the French were more successful from the late 1990s and that "short termism" by British financial institutions was a key factor in the relative decline of British-owned game publishing. ${ }^{39}$

In terms of employment in the games industry in Europe, the UK is the largest employer $\left(20,000\right.$ people), followed by France $(15,000)$ and Germany $(19,000) .{ }^{40}$ Figures for direct employment in games development (excluding retail and publishing) are somewhat lower and, in the UK, are estimated to be almost 10,000. However, in all these countries, the numbers of companies have declined in the past ten years and there has been significant turmoil leading to closures, mergers and takeovers. Employment numbers however appear to have remained steady which indicates that development companies are getting larger. A recent UK report

35 See http://kotaku.com/5030320/here-are-the-top-20-publishers-in-the-business-ranked-according-tocash-money-intake.

36 Dmitri Williams, "Structure and Competition in the US Home Video Game Industry" (2002) The International Journal on Media Management 4:1, pp. 41-54.

37 Scott Gallagher and Seung Ho Park, "Innovation and Competition in Standard-Based Industries: A Historical Analysis of the US Home Video Game Market" (2002) IEEE Transactions on Engineering Management 49:1, pp. 67-82.

${ }^{38}$ Spectrum, From Exuberant Youth to Sustainable Maturity: Competitiveness Analysis of the UK Games Software Sector, 2002, available at http://www.berr.gov.uk/files/file10663.pdf, at pp. 37-39.

${ }^{39}$ Philippe Larrue, William Lazonick and Mary O'Sullivan, “European Competitors in the Video Game Industry: Venture Creation and Enterprise Growth in France and Britain", Paper presented at the Conference "Playing with the Future: Development and Directions in Computer Gaming", 5-7 April 2002, Centre for Research on Innovation and Competition, University of Manchester.

40 Spectrum, supra note 38, at p. 20. Numbers employed are for 2000. By 2005 the numbers had fallen to 10,000 in Germany according to Teipen, supra note 34, at p. 317. 
noted that the UK has slipped to the fifth place in terms of employment in games behind the US, Japan, Canada and Korea. ${ }^{41}$

In many of the core game development industries, like those in the US and the $\mathrm{UK}$, there is very low gender, ethnic and age diversity in the workforce. In the UK the latest Skillset census noted that $12 \%$ of employees in the games industry were women, and that this varied greatly by occupation. Less than $4 \%$ belonged to an ethnic minority. ${ }^{42}$ In the latest International Game Developers Association (IGDA) online survey of the demographics of game developers, just under $12 \%$ were identified as female and were predominantly employed in human resources, sales and marketing. The qualitative report on comments made by the male respondents would suggest that gender diversity in the workforce is not a priority for male workers. ${ }^{43}$ While increasing the numbers of females in the workforce will not necessarily lead to institutional or content changes, it is still an important issue that needs to be considered when one is examining cultural diversity in games. ${ }^{44}$ The working conditions in some games companies may also militate against greater diversity in the work force. Long hours especially coming up to "crunch time", relatively low pay and precarious contracts have been noted in some major multinational companies and these "quality of life" issues are viewed by many as incompatible with family life or indeed with a sustainable work/life balance. ${ }^{45}$

As detailed in Christoph Graber's contribution to this volume, an increasing number of countries have introduced production support schemes, tax incentives, travel support funds and regional innovation support schemes including Canada, France, Germany, Turkey, Korea and some Nordic states. Even countries which have traditionally supported free trade, like the US and the UK, have introduced regional or state level support for their games industry. The Game Republic organization in Yorkshire, UK and Creative Scotland initiatives in particular illustrate that companies have joined together with regional development agencies to promote their local games industry. ${ }^{46}$ More recently, TIGA ${ }^{47}$ and the Entertainment and Leisure Software Publishers Association (ELSPA), the bodies responsible for development and publishing, respectively, in the UK have formed "Games Up" to lobby the government to introduce a tax break similar to that enjoyed by the film industry. ${ }^{48}$ They also commissioned a report on the economic contribution of the games industry to the UK economy written by Oxford Economics which helps to make a case for support based on increasing competition from other "subsidised territories". ${ }^{49}$

${ }^{41}$ Oxford Economics, The Economic Contribution of the UK Games Development Industry, Oxford: Oxford Economics, 2008.

${ }^{42}$ Skillset Employment Census 2006, available at http://www.skillset.org/research/census.

43 This survey was answered mainly by developers in North America. See http://www.igda.org/diversity/report.php.

${ }^{44}$ Liesbet van Zoonen, Feminist Media Studies, London: Sage, 1994.

${ }^{45} \mathrm{Kline}$ et al., supra note 16; Dyer-Witheford and Sharman, supra note 21.

${ }^{46}$ See http://www.screenyorkshire.co.uk/games/.

${ }^{47}$ The UK trade association representing the interests of games developers in the UK and Europe. See http://www.tiga.org.

${ }^{48}$ See Steve Boxer, "Games industry: Arrested Development", The Guardian, 23 October 2008.

${ }_{49}$ "[L]ong term decline in the UK based industry is a real possibility - this year has seen the loss of development jobs from global publisher studios. If the trend of global publishers downsizing in the UK continues - exacerbated by the relocation of the most threatened low level jobs (QA and testing) by global publishers to other territories, then these losses will no longer be absorbed by existing studios and the industry will suffer. [...] The UK has traditionally been the third largest development territory in the world in terms of revenue generation, but has recently slipped to 5th place - behind Canada and Korea, including network games due to, among other factors, increasing competition from subsidised territories. The amount of new IP 
Over the last five years we have seen ISFE, the European publishers association, object strongly at a European level to French and German attempts to introduce support for domestic games production on cultural grounds. ${ }^{50}$ Nevertheless such schemes have been introduced. The French tax credit scheme, for example, has a points system to determine the cultural content of a game based on criteria such as language, levels of artistic expenditure, links to European historical, artistic or scientific heritage. ${ }^{51}$ Even in countries where policy has traditionally focused on technology and innovation rather than cultural aspects of games there is now an emerging discourse around the cultural benefits, albeit, national cultural benefits, of games production. The recent Oxford Economics report has a section on "cultural benefits" and claims that games have an impact on national branding and an indirect impact on other industries like tourism.

... if the industry in the UK was to decline, there would be a loss to society as these distinctive 'British' traits would not be found in the games made somewhere else. Further, the UK 'country-branding' projected by the video games could serve to reinforce the image of the country as a tourist destination (i.e. through images of landscape, landmark buildings), technological reputation, or cultural values. Moreover, this effect may be even stronger than other mediums such as film, given the longer exposure involved in video games, as a single title is consumed for a greater duration than a film or a TV programme. ${ }^{52}$

In sum, what we can see emerging in the available data is that publishing is increasingly concentrated and that in the console segment of the market a very small number of American and Japanese companies dominate and are growing larger through acquiring publishers and developers from other countries. While production of games and hardware is increasingly spatially distributed, this movement has been towards lower cost locations and higher value added functions and decision making is retained in-house and located predominantly in the US, Japan, the UK and France as well as in the rapidly growing South Korean and Canadian industries. In the rest of Europe, certain countries have large individual companies, especially Germany, Sweden and Finland, but their power in relation to the global market is limited. Research on the games industry in Ireland would suggest that it is very difficult for independent content developers to enter the marketplace, particularly when it comes to developing original games. ${ }^{53}$

Most European countries have a negative trade balance and import more games than they export: games are published and mostly developed by the American and Japanese companies that dominate in European markets. What data we have would suggest that the PC segment is quite large in Europe, but it is still largely dwarfed by the value of the console segment, especially if you include handheld devices in this category. Nevertheless, there are more opportunities for increased diversity of production in PC and casual games, although independent data on these sectors is lacking. The development of alternative distribution platforms like the iPhone and Kongregate ${ }^{54}$ also provides for increasing numbers

made in the UK and reaching the market is decreasing, despite the size of both the global and UK retail market increasing at double digit figures, and the boom of online and mobile games, that have largely bypassed the UK". Oxford Economics, supra note 41, at pp. 2-4.

50 See http://www.isfe.eu.

${ }^{51}$ Commission Decision of 11 December 2007 on State Aid C47/06 (ex N 648/05), Tax credit introduced by France for the creation of video games 2008/354/EC, OJ 2007, L118/16.

52 Oxford Economics, supra note 41, at p. 42.

${ }^{53}$ Kerr, supra note 32 and Aphra Kerr, "Live Life to the Power of PS2: Locating the Digital Games Industry in the New Media Environment" (2003) Irish Communications Review 9.

${ }^{54}$ See http://www.kongregate.com. 
of casual games from greater numbers of individuals and countries. Other online distribution services like Steam offer digital rights management platforms, automatic updates and developer support services for both independent and full commercial developers. ${ }^{55}$ These may lower barriers to entry but may not have a significant impact upon diversity if existing generic conventions are maintained.

The digital games production industry is divided into three "techno-regions" which are enforced through technical, business and, to some extent, social practices. Thus games priced and targeted at the American market are not meant to be sold or downloaded in the Western European or Asian Pacific markets. The geography of games production, especially of the games themselves, stretches between the US and Japan with significant nodes in South Korea, the UK, France and Canada. In Europe, countries like the UK and France have been losing ground in terms of numbers of companies, numbers employed and numbers of games produced to emergent production centres like Canada, South Korea and China. To counteract this, both developers and publishers associations at national and regional levels in Europe have been attempting to lobby governments to introduce funding support. France, Scandinavia and the MEDIA programme of the European Union have attempted to extend existing funding programmes to include games and have attached cultural and public interest criteria to this funding. In the UK, the focus has been on funding for technological innovation although the "cultural benefits" argument is now also being invoked. Lobbying for public support has led to increasing attention being paid to the range of games produced and the multiplicity of cultures, characters and ideas expressed in these games, to which we now turn.

\section{The cultural diversity of content}

It is clear from the available data that the number of digital games, or the multiplicity of games, available via a variety of channels has been growing rapidly. Given this situation, it is not possible in the space we have to consider cultural diversity at a character level or in terms of diversity of opinions and politics. Based on existing secondary information we can however explore the diversity of genres by market and platform and the mobility and flow of these genres across markets. It is also clear that a small number of games sell very well in particular markets and an even smaller number of games sell well across multiple markets and develop into franchises and sequels. Examples of games that sell well across multiple markets and that have become major franchises include The Sims, Pokemon, Mario, Metal Gear Solid, Grand Theft Auto and Final Fantasy. ${ }^{56}$ Most of these games require some degree, if not extensive, localisation before they are shipped to different language markets and other supra-regional contexts.

A range of cultural influences can be traced in digital games. Aoyama and Izushi claim that manga have had a significant influence on Japanese games. ${ }^{57}$ Others have written about the British humour in games produced in the UK or the Nordic themes used in games from Scandinavia. ${ }^{58}$ Not all cultural influences can be

55 See http://store.steampowered.com.

56 There are few reports that analyse game sales across multiple markets although there is now data referring to console game sales in the US, the UK and Japan. See http://www.npd.com/ press/releases/press_081110a.html.

${ }^{57}$ Aoyama and Izushi, supra note 21.

58 Oxford Economics, supra note 41. 
attributed to 'national' cultures. Indeed a game like Grand Theft Auto can be fictionally set in cities modelled on Los Angeles or New York, but was in fact originally developed in northern Scotland. Mia Consalvo has written about the "hybrid" mix of Japanese and American cultures in the Final Fantasy games. ${ }^{59}$ These "hybrid" games are carefully designed and localised with the Western/US market in mind but attempt to keep some Japanese pop cultural elements as well. “Blending Tidus's western surfer boy looks with Wakka's Jamaican accent, and faux-traditional Japanese styles such as Yuna's revealing kimono, the game (Final Fantasy $\mathrm{X}$ ) appeared a blending of world cultures, down to the trade winds and tropical islands characterising the world". ${ }^{60}$

Not all games are carefully localised or able to move without difficulty between markets. Academic and press reports point to the cultural specificity of many games and the cost and cultural difficulties companies face when trying to localise games for different markets. ${ }^{61}$ What scholarship exists relates mostly to the failure of Japanese or Asian games to be localised for Western markets and the complex barriers to circulation for Western companies attempting to enter certain Asian markets, many of which have as much to do with business as with cultural barriers. Apart from sports games which can be quite specific to particular markets, it is apparent that many Japanese games are not exported to Western markets and that first person shooter games have not traditionally sold well in the Japanese market.

When we analyse game sales by genre it is apparent that player preferences vary by genre, by market segment and by market. Thus while first person shooter games dominate on the Xbox 360 in the US, a mix of action, adventure and sports dominates on the PS3 while adventure and mini games are most popular on the Wii. ${ }^{62}$ In Japan PS3 and Wii game sales dominate and as such Pokemon, Mario and Wii games do also. The top selling console games in Japan are dominated by Sony and Nintendo titles. The only third-party games, i.e. games developed by independent companies, to make the top ten in Japan in 2008 were Metal Gear Solid 4 (Kojima) and Monster Hunter 2G (Capcom), both produced by Japanese companies. Further, many games combine genres or create new genres so in fact games like Grand Theft Auto IV (2008) could be classified as an action, adventure, driving, shooter while something like The Sims (2000) almost created a genre of its own.

Data provided by the US Entertainment Software Association (ESA) notes that the top selling genres by units sold of video games in the US in 2007 saw action $(22.3 \%)$ and family $(17.6 \%)$ as the most significant followed by sports $(14.1 \%)$ and shooters $(12.1 \%)$. In PC games the order was strategy $(33.9 \%)$ and family $(14.3 \%)$ followed by role playing $(18.8 \%)$ and shooters $(11.6 \%)$. When it came to online game playing, puzzle and card games $(47 \%)$ and action sports $(16 \%)$ were the most popular. MMOGs only constituted $11 \%$ of PC games. ${ }^{63}$ In Korea a survey of gamers (rather than of unit sales) indicates that console sports games $(36.6 \%)$ dominate, followed by action $(16.7 \%)$ and role playing games $(13.3 \%)$. For online gamers role

${ }^{59}$ Consalvo, supra note 22.

${ }^{60}$ Ibid. at p. 118.

61 Carmen Mangiron and Minako O'Hagan, "Game Localisation: Unleashing Imagination with ‘Restricted' Translation” (2006) Journal of Specialised Translation 6, pp. 10-21.

62 See http://www.gamasutra.com/view/feature/3795/2008s_topselling_games_so_far_php.

63 Entertainment Software Association (ESA), "Essential Facts about the Computer and Video Game Industry: 2008 Sales, Demographic and Usage Data", ESA, July 2008, available at http://www.theesa.com/facts/pdfs/ESA_EF_2008.pdf. 
playing games dominate (35.8\%) followed by web/puzzle $(20.3 \%)$ and casual games. However, these surveys include a range of genres which do not exist in US or UK surveys including "competitive action fighting games", "adult only betting" and "somesthesia games", and they have three fighting categories: first person shooters, shooting, and competitive fighting action games. ${ }^{64}$ What all these studies indicate is that mature and adult games constitute less than a quarter of games on most platforms and less on some, that first person shooter games are most popular in the US and on Xbox 360 and are rather a niche genre on other platforms and in other countries. Finally, there are some genres which appear to be market specific and do not get exported to other markets. All of these issues add greatly to the complexities faced by regulators and academics trying to understand the range of texts and representations produced.

The available evidence would suggest that certain genres dominate in certain markets and the market is providing variations on action, strategy, shooter and role playing games. A new genre of music and dancing games is also growing rapidly and falls within the family category of games. Nevertheless, there are gaps. It is apparent that despite the enthusiastic embrace of games as a motivational and accessible tool for teaching a range of subjects in schools, many teachers and academics find that "commercial off the shelf games" (COTS) are not suitable for use in a classroom situation at pre-university levels. Problems range from inaccuracy of historical or other details in the game to technical and support difficulties. ${ }^{65}$ However, to date most educational game content and research, with the exception of some programmes in the US, has developed as a result of public investment rather than commercial interest. For example, the US Army has invested significant amounts in training, simulation and games related research. ${ }^{66}$ The recent development of brain training games on the Nintendo DS is an indication that education related games can be commercially successful in certain narrow topic areas. However, there are relatively few educational/serious games developed by the commercial games industry for video console and PC.

By comparison, there has been a recent blossoming of casual games, particularly those available via the web, but also via mobile phones and for download. Here web/puzzle, card games, action/adventure dominate followed by role playing games. ${ }^{67}$ In terms of games played on $3 \mathrm{G}$ mobile phones in the US action/adventure, first person shooter and sports genres are among the least played genres. Again, time management, finding objects, card/casino and puzzle games dominate. In casual games in the US there is certainly a multiplicity of titles but there is relatively rapid turnover, i.e. top selling games are replaced quite quickly with new games, and a good range of companies is involved. When we

\footnotetext{
${ }^{64}$ KGDI, The Rise of Korean Games. Guide to Korean Game Industry and Culture, Korean Game Development and Promotion Institute, 2006. See http://www.kogia.or.kr/index.jsp.

65 Angela McFarlane, Anne Sparrowhawk and Ysanne Heald, Report on the Educational Use of Games, Department of Education and Skills and teem (Teachers Evaluating Educational Multimedia), 2002, available at http://www.teem.org.uk/publications/teem_gamesined_full.pdf; Kurt Squire, "Cultural Framing of Computer/Video Games" (2002) Game Studies 2:1. Kurt Squire and Sasha Barab, "Replaying History: Engaging Urban Underserved Students in Learning World History Through Computer Simulation Games", Proceedings of the 6th International Conference on Learning Sciences, Santa Monica, California, 2004; Simon Egenfeldt-Nielsen, "Practical Barriers in Using Educational Computer Games" (2004) On the Horizon 12:1, pp. 18-21.

${ }^{66}$ Shenja van der Graaf and David B. Nieborg, "Together We Brand: America's Army" in Copier and Raessens, supra note 17, pp. 324-338.

67 For quite a US based account, see http://www.igda.org/casual/IGDA_
} 
look at diversity within games, things are a little more complicated and it is difficult to make definitive statements without more in-depth analysis. Similarly there has been little analysis on the linguistic diversity of games although the rise of Asian game developers would suggest that an increasing number of Asian languages may be represented in game content and developments in Internet governance to allow for instance for non-Latin based language domains, will no doubt help in this regard. 68

The development of user generated content and accessible digital production tools complicates matters further. The use of modding tools to modify copyright materials is strictly limited under terms and conditions (ToC) and end-user licence agreements (EULA). Ownership of the content developed with the tools may rest with the publisher/developer of the original game and users may not infringe the rights of other copyright holders. This has not stopped users trying to develop new ways to modify commercial game content or developers from developing new ways to exploit game players' time and labour. ${ }^{69}$ Further, shifting the burden for creating diverse character representations that satisfy market demands onto the user while maintaining control over what is done with those representations is likely to have a limited overall impact on diversity of content.

What is clear is that we are seeing the consolidation and growth of genres like action, sports, family and strategy in Western markets and the emergence of new genres like music and dance in the console and PC segment of the market. Genres are important in terms of marketing and positioning a game in the marketplace and developers are usually encouraged by publishers and other gatekeepers to develop games that match particular genre types. The casual games space is still very much in flux and while puzzle/card and object finding games dominate in the US, gambling and skill type games are most popular in Asian markets. Across all platforms and markets, a small but growing genre is that of mature/adult based game content, signalling that digital games are no longer just for children or young people. While the industry is increasingly providing content aimed at adults, families and real world training simulations, certain genres of content are not readily available and this is particularly evident in relation to educational/serious games related to school curricula.

While there may be an increasing number of game genres across the different platforms and across markets, game characters, gameplay and game stories have been heavily criticised from a number of corners for their exploitation of "militarised masculinity", the restricted range of roles for female characters and the highly sexualised representations of women. ${ }^{70}$ Further, attempts to attract more females to play games have led to further essentialising of game content through the production of "pink games" and the development of games to tie into existing media licences like Bratz and Barbie. ${ }^{71}$ We must be careful however about picking out individual titles and making general claims about all games based on that evidence. Further, we need to be careful about making generalisations across different regional markets. It is clear that there are games that attempt to exploit

68 See http://www.icann.org/en/topics/idn/.

${ }^{69}$ Julian Kücklich, "Precarious Playbour: Modders and the Digital Games Industry" (2005) Fibreculture, Issue 5. Sal Humphreys, "Ruling the Virtual World: Governance in Massively Multiplayer Online Games" (2008) European Journal of Cultural Studies 11:2, pp. 149-171; David B. Nieborg and Shenja van der Graaf, "The Mod Industries? The Industrial Logic of Non-Market Game Production" (2008) European Journal of Cultural Studies 11:2, pp. 177-195. See also Mira Burri-Nenova's contribution to this volume.

${ }^{70}$ Skirrow, supra note 16; Kline et al., supra note 16.

${ }^{71}$ Cassell and Jenkins, supra note 15. 
military and masculine themes, are very violent and present women in demeaning roles and dress. However, there are now games where there are empowered female roles or non-human characters and which have no violence at all. Studies of game play meanwhile highlight how both adult men and women strategically deploy their avatars within game contexts, modify their game characters or bracket their appearance and role within a game. ${ }^{72}$ Increasing levels of critical attention from academics and regulators will no doubt continue to keep this issue at the forefront of attention. ${ }^{73}$

Across media systems in Europe, governments have moved away from censorship of content and developed various types of co-regulatory and selfregulatory systems, especially in relation to new media. To date there has been little evaluation of the application and working of these self-regulation systems. The extension of the Pan European Game Information (PEGI) system and the development of PEGI Online in Europe, for example, is welcome but there has been little independent examination of how this system works on the ground, how compliant publishers and retailers are with the need for enforcing and informing customers about the system, how accurately the advertising of games conforms to the system and how participants use player data. Studies of how specific games are rated differently in different countries point to some variance between the application of these ratings across regions. ${ }^{74}$ Most rating systems have an adult or mature rating for games but there are varying sensitivities between systems as to which games should receive such a rating. Violence and sexual content are the main causes of concern in Western countries, Australia and Japan, particularly in terms of access and their potential impact on minors. Certain types of 'harmful' content in virtual environments are also subject to the same national laws as content on 'legacy media' regulatory systems. ${ }^{75}$ There appears to be less concern from regulators in relation to games based around betting, gambling and trading. Further, little is said about linguistic and cultural diversity and player rights in terms of user generated content. ${ }^{76}$

\section{The cultural diversity of game players}

Digital games are complex pieces of software, as increasingly are all cultural products. ${ }^{77}$ User control is important across digital media products and, in virtual worlds, avatars offer a visual representation of complex sets of powers and skills to enable the user to navigate the game. Nevertheless, this control is carefully scripted by the rules of the games. Games borrow certain elements and influences from books, films and television but also extend the possibilities for engagement in new ways. Research conducted by this author in Ireland into the pleasures of digital game play found that control, immersion and performance were of primary importance to players, followed by narrative and intertextuality with other media

${ }^{72}$ Bryce and Rutter, supra note 17; Helen W. Kennedy, "Lara Croft: Feminist Icon or Cyberbimbo? On the Limits of Textual Analysis"' (2002) Game Studies 2:2.

${ }^{73}$ For detailed analysis, see Sabina Misoch's contribution to this volume.

${ }^{74}$ Aphra Kerr, "Spilling Hot Coffee? Grand Theft Auto as Contested Cultural Product" in Nate Garrelts (ed.), The Meaning and Culture of Grand Theft Auto, Jefferson, NC: McFarland Press, 2006, pp. 17-34.

${ }^{75}$ RXX Collins, "Internet Governance in the UK" (2006) Media, Culture \& Society 28:3, pp. 337-358.

76 See http://www.pegionline.eu/en/index/id/media/pdf/197.pdf. See also the contribution of Miriam Sahlfeld to this volume.

77 See the contribution of Christoph Beat Graber to this volume. 
texts. ${ }^{78}$ Most of these pleasures were mediated by the social context of play, the players' experience and competence, length of time spent playing and demographics. What this work indicates is that to study games as texts or representations is not sufficient to understand their "effect" in the real world. This is not to say that games have no "effect" but rather to problematise the causal relationship and question work conducted in laboratory situations over limited time periods. Further, the reasons why people play in one context and culture may differ from the reasons in another. A survey of gamers in the US by the ESA noted that the main reason people gave for playing games was for "fun" while in Korea it was the "story" or the "graphics". ${ }^{79}$ Stage of life is also important to understanding the game play experience and the amounts of time devoted to game play. The time available to play and the play experience in childhood or in college is quite different from when one starts a family.

As mentioned earlier, a report on global trade flows by UNESCO in 2005 found that most exports of games were going to a limited number of high income countries dominated by the USA and followed by France, Germany, Hong Kong, China and the UK. The report also suggested that what data exists on trade in audiovisual services would suggest that the US dominate in this area followed by the UK. And who plays games in these markets? Again, it depends on the game platform and genre. The industry itself provides statistics showing that an increasing number of older players and women are playing games, although it fails to break these demographics down and give details on what particular games were played frequently or "ever". The ESA in the US notes that about two-thirds of players questioned in a recent survey of gaming households were under 50 years old and $40 \%$ of women "play", but the study fails to give any detail as to what "play" means. ${ }^{80}$ The report said nothing of the ethnic or racial origin or ability or disability of those surveyed.

A rather more representative survey conducted by the BBC in the UK, which sampled for demographic, ethnic and geographical diversity, found that almost $60 \%$ of $6-65$-year-olds were gamers, defined as someone who had played a game in the previous six months. Gamers were then divided into light, medium and heavy gamers, and there were significant genre differences by gender and age. Action/adventure was the most popular genre with 6-10-year-olds while simulations topped the list with 11-15-year-olds, closely followed by action/adventure and racing, followed by simulations with 16-24-year-olds. With 25-35 and 36-50-year-olds puzzle/board games topped the list, followed by action/adventure. When asked about their favourite games, both genders liked MMOGs and strategy games, whereas more females preferred puzzle/board games, music/dance and classic games and more males preferred action/adventure, shooting, racing and sports. The older age groups in this survey felt that the market was oversaturated with fighting, shooting and racing games. Of the younger game players, most played in the living room while teenagers were more likely to play in their bedrooms.

Meanwhile a report from Korea found that while playing at home is important, Internet cafes are a popular location for game playing. The numbers playing by age group are slightly less than in the UK, although they decrease with age in the same

\footnotetext{
${ }_{78}$ Aphra Kerr, Pat Brereton, Julian Kücklich and Roddy Flynn, "New Media: New Pleasures?" (2006) International Journal of Cultural Studies 9:1, pp. 63-82.

${ }^{79} \mathrm{KGDI}$, supra note 64 , at p. 65; ESA, supra note 63 , at p. 7.

${ }^{80} \mathrm{ESA}$, supra note 63.
} 
way as they do in the UK. Further the most popular platform is "online game" 81 and the most popular genres again showed gender differences but overall web/board games and role playing games were the most popular. ${ }^{82}$ Interestingly male respondents preferred role playing games (35.3\%) and strategy simulation games $(14.2 \%)$, whereas female respondents preferred web board games $(31.9 \%)$, role playing games $(22.4 \%)$, and casual games $(19.9 \%)$. As noted above, there is a greater range of genres in this survey.

The surveys conducted by the ESA and the KGDI are essentially for promotion purposes while the $\mathrm{BBC}$ is obviously interested in convergence between digital games and their core audiovisual businesses. Meanwhile academics have been conducting both qualitative and quantitative surveys to try to understand better the playing habits of gamers and the constraints and contexts surrounding gaming. In line with audience/reception research more generally, this work acknowledges that media influence is mediated by a range of contextual factors and that a small number of game players are intensive, heavy or addicted game players. Further, the more sociological work explores individuals in their social contexts of play and how play is mediated by other factors. Ethnographic studies of game culture in the UK and Ireland meanwhile point to the role of gendered games advertising in the mainstream media and the gendering of public game spaces as a key part of the wider gendering of game culture. ${ }^{83}$ Domestic game playing by females also tends to be mediated through male networks or male family members.

Research on online game culture, some of which takes place in Internet cafes and some of which takes place in domestic settings, further complicates the issue. It is important to note that digital games are not the same thing everywhere or indeed accessed and played in the same ways everywhere and that we need to attend to these differences to understand some of the gaps that are emerging. While there is evidence from industry surveys that increasing numbers of women play online games, there is also evidence that many game players experience sexist, racist and other offensive language and behaviour in these spaces even if the game itself allows one to hide gender markers. ${ }^{84}$ Outside the game playing space, little attention has been paid to the role of retailers (offline and online) in the presentation and construction of identities surrounding digital games. Both independent and multiple retailers play an important role in terms of the presentation, construction and regulation of access to digital games. Online retail and distribution services are emerging as alternative sources of digital games but these will also play a role in the construction, or not, of culturally diverse game playing cultures.

${ }^{81}$ KGDI, supra note 64 , at p. 51.

82 Online games are defined in this report "regardless of type of distribution, type of platform, location of the server (only domestic), wire / wireless (including network and mobile games), and fee-based or no-cost. There are two types of online games, which are the 'Online game' that is played online through a PC (Personal Computer) or Video (console), and 'Mobile games,' that use wire/wireless communication functions of mobile devices, such as cellular phones, PDA, portable game devices, etc." (KGDI, supra note 64, at p. 17).

${ }^{83}$ Gareth R. Schott, Kirsty R. Horrell, "Girl Gamers and their Relationship with the Gaming Culture" (2000) International Journal of Research into New Media Technologies 6:4, pp. 36-53; Bryce and Rutter (2003), supra note 17; Helen J. Gansmo, Hege Nordli, Knut Sørensen, "The Gender Game: A Study of Norwegian Computer Game Designers" in Paschal Preston and Carol MacKeogh (eds.), Strategies of Inclusion and Gender in the Information Society: Private and Voluntary Sector Initiatives, Trondheim: NTNU Press, 2003, pp. 115-139; Kerr, supra note 53; T.L. Taylor, "Multiple Pleasures: Women and Online Gaming" (2003) Convergence: The Journal of Research into New Media Technologies 9:1, pp. 21-46.

${ }_{84}$ Talmadge Wright, Eric Boria and Paul Breidenbach, "Creative Player Actions in FPS Online Video Games" (2002) Game Studies 2:2; T.L. Taylor, Play Between Worlds: Exploring Online Game Culture, Cambridge, Mass.: MIT Press, 2006. 


\section{Findings and Implications for Regulation}

We have noted in this chapter that cultural diversity has been a goal of mass media policy in many European countries for the past half a century. Recent policy developments at international bodies like UNESCO and governance initiatives by self-regulatory bodies like ICANN demonstrate that the concept of cultural diversity is also emerging in relation to the production, distribution and use of new media. How this concept is deployed, however, has changed over time and increasingly academics are moving away from a discourse associated with 'national cultures' and towards a discourse based on cultural citizenship, cultural rights, and diasporic, indigenous and sub-cultural rights. In relation to the media, the discourse has tried to focus on cultural diversity as a normative ideal which needs to inform policy and practice in relation to content production, distribution and use. While there appears to be no resistance to applying this in relation to the mass media in Europe, there is some resistance to applying this concept and associated policies to transnational media and especially in relation to new forms of content like digital games.

Digital games, as digital applications and services accessed via standalone and online platforms, combine elements of traditional cultural industries with elements of software. Digital games are increasingly available transnationally and they are lightly and largely self-regulated in relation to content. This chapter has examined some of the available evidence on the cultural diversity of digital game production, distribution and use. The evidence is far from straightforward or complete. We have found that digital games console production is concentrated and controlled by a small number of companies primarily in the US and Japan. These companies have developed three supra-regional markets with economic, business, political and cultural barriers to circulation of texts between them. As the major console platforms move online there will be increasing incentives to exploit the network economies generated. The PC and casual games markets are marked by plurality and flux, but even here new intermediaries and gatekeepers are emerging and there are a range of barriers to content moving between markets. New distribution channels currently offer lower barriers to entry but increasing access will not in itself lead to greater diversity of content.

Game development companies and publishers in Europe are consolidating and trying to grow in size but are currently failing to challenge the top five companies in terms of turnover, profit and unit sales. While the console games industry sees cooperation and competition between US and Japanese companies, there is more diversity in other segments. A key trend since the beginning of the last decade has been the degree to which independent studios have been bought by the major publishers and hardware manufacturers and the degree to which content in these companies is therefore dictated by a publishing schedule and practices and conventions of a smaller and smaller number of 'major' companies. Digital game producers and publishers also target the largest markets and these are currently the US, the UK and certain Asian countries. For European producers, success in the US and UK markets is vital, and consumption patterns in these markets have a significant influence on game content produced across Europe. Funding game development in subsidiaries of foreign owned companies may generate jobs in European countries, but is likely to do little to address cultural diversity in 
European terms when the target markets are the US and the UK. A further worrying issue is the lack of diversity in terms of the workforce, particularly in the US and the UK, where young, white, male workers dominate. While there is no simple relationship between gender and racial diversity of the workforce and content production, particularly given the decision hierarchy in digital games production, workplace diversity is something that the industry needs to address more seriously.

When it comes to content and users, the three supra-regions display a range of interesting differences. The range of genres in American and European markets is quite similar but differs quite considerably from the range in Asian markets. These differences in part stem from different tastes and cultures, but cultural specificities in games and localisation costs are both disincentives to flow between regions and depending on the size of the markets in question companies tend to try to minimise cultural specificities and localisation costs. While market demand seems to ensure a ready supply of certain action, racing, sports and gambling genres, other genres, such as education related games, are not emerging to the same degree. Genres are seen as important marketing tools for the games industry but many games fall within multiple genres and genres may be defined differently in different markets. Games development is influenced by both local and global cultural influences but the flow of games between markets is influenced as much by technical and cost barriers as cultural barriers. Some of these barriers should be examined to see if the circulation and internationalisation of certain types of games from certain markets could be facilitated. National and regional initiatives are now emerging which are attempting to support financially, and through other instruments, the development of local games production but only some of these instruments overtly consider the genre and cultural diversity of that content. More attention needs to be paid to supporting alternative or new genres of games while also taking into account the working conditions and workforce of the companies funded.

Finally, when it comes to the cultural diversity of audiences, there are clearly a range of issues. Of concern here is that public gaming spaces and online spaces in Western cultures tend to be highly gendered and this is reinforced by certain types of advertising, promotion and retailer activities. These social processes operate equally, if in different ways, in online as well as real world spaces. The development of professional game competitions and public gaming spaces needs to be examined in this regard. Equally game servers, portals and websites need to become more aware of the gender, race, linguistic and cultural diversity of their users and use the player data that they are gathering for positive inputs into game and interface design in addition to their existing use for marketing and player control purposes. In many European markets, a very large percentage of children and young adults play digital games. To date self-regulatory systems and existing laws have focused on protection of minors and little is known about how they function in practice. There would appear to be a need to do more than merely inform consumers about existing content by actually examining ways to foster and support culturally inclusive games spaces and a range of game content for players.

In considering policy interventions in relation to digital games, we must therefore pay attention to the global political economy of the industry: who are the key players; how do games get commissioned and to market; who plays them and where? National inventions in relation to supporting commercial digital games production must do more than merely increasing the spatial diversity of 
production and increasing the trade balance in terms of documented flows between Europe and the US and Japan. Policies must attend to the complexities of this sector as a highly regionalised cultural industry that operates differently across its markets as well as across its various sub-sectors, i.e. the console, PC, MMOG and casual sectors. In order to encourage cultural diversity in digital games, European policies should go beyond attempts merely to preserve and protect 'national cultures' to develop specific policies to address gaps in current content provision, to support independent producers to develop original ideas for European markets and to support the internationalisation and localisation of content. They might also consider initiatives that pay attention to supporting programmes to encourage greater cultural diversity and inclusiveness in European games education, retail and consumption spaces. 